\title{
CORK MEMBRANE FOR EFFICIENT OIL AND WATER SEPARATION
}

\author{
Yanbiao Zhou*, Binghua Liao, Kaige Qu, Lihui Zhang and Luyang Ye \\ School of Chemistry and Environmental Engineering, Pingdingshan University, Pingdingshan 67000, China
}

Recebido em 08/01/2018; aceito em 11/04/2018; publicado na web em 09/05/2018

\begin{abstract}
Cork is a renewable, biocompatible, environmentally friendly and abundant biological material with microscale cellular structure. Fabrication of filtration membranes for the separation of oil and water by utilizing such natural materials to replace nonnatural membranes is a green method. A cork membrane with a water contact angle greater than $150^{\circ}$ and an oil contact angle close to $0^{\circ}$ was fabricated by chemically modifying cork membranes with $1 \mathrm{H}, 1 \mathrm{H}, 2 \mathrm{H}, 2 \mathrm{H}$-perfluorodecyltrichlorosilane. The special wettability was achieved owing to the cellular structure and the surface composition of the cork membrane. Just like nonnatural filtration membranes, natural cork membranes exhibited excellent permeability for oils. After at least 40 cycles of oil-removal processes, the separation efficiency of the membrane was still above $99.1 \%$. Under harsh conditions such as strong acid/alkali, high humidity, and high temperature environments, the wettability and separation efficiency exhibited excellent stability and durability. This method offers an opportunity to the practical applications of the superhydrophobic cork membrane.
\end{abstract}

Keywords: cork; cellular structure; special wettability; separation of oil and water; harsh conditions.

\section{INTRODUCTION}

Inspired by the special wettability of natural materials such as lotus leaves and water strider legs, ${ }^{1}$ many biomimic filtration membranes with superhydrophobic and superoleophilic properties have been developed. A typical approach for creating such membranes is to fabricate filtration supports with channels at the nano- or/and micrometer level, and then modify the membrane with various low surface-energy materials. Generally, metal meshes, ${ }^{2-5}$ polymer membranes, ${ }^{6,7}$ fabrics,${ }^{8,9}$ and paper, ${ }^{10,11}$ etc. are used as filtration supports. These support materials are all artificially prepared or plant-derived materials. Compared with these materials, plant materials are renewable, biocompatible and abundant. Many plant materials possess outstanding mechanical properties and oriented hierarchical structures. ${ }^{12}$ These features make them great potential as novel filtration supports. However, to the best of the authors' knowledge, no studies involving plant filtration membranes with both superhydrophobic and superoleophilic properties have been reported to date.

Cork is a natural material which is isolated from the bark of cork tree every 9-12 years. Its cellular structure and chemical composition confer itself with many unique properties, such as high porosity, low permeability and hydrophobic behavior. Cork has been used to fabricate sealing, floating, acoustic, insulation, absorption and surfacing products, such as wine stoppers. ${ }^{13,14}$ Herein, we fabricated a filtration membrane by modifying cork with $1 \mathrm{H}, 1 \mathrm{H}$, $2 \mathrm{H}, 2 \mathrm{H}$-perfluorodecyltrichlorosilane (FDTS). The typical procedure to create the cork membrane is presented in Figure 1. The cork was cut into membranes by a circular saw. Before silanization, the membrane was hydroxylated in $20 \% \mathrm{H}_{2} \mathrm{O}_{2}$ to obtain more hydroxyl groups, which was essential for the silanization process. After that, the membrane reacted with low surface energy molecules to reduce the surface energy. The special wettability completely stops water to pass while permits oils to permeate freely. So, the membrane with the special wettability and porous channels could successfully separate the oil and water mixture.

*e-mail: 349633279@qq.com

\section{EXPERIMENTAL}

Typical boiling treatment as used by stopper manufacturers was performed to cork planks, which were provided by cork stopper manufacturer. Firstly, good-quality corks were sawed into membranes with a thickness of about $2.0 \mathrm{~mm}$ and then soaked in distilled water and ethanol for $1 \mathrm{~h}$ for three times respectively to remove possible soluble compounds and sawdust, followed by drying them in an oven at $60{ }^{\circ} \mathrm{C}$ for $12 \mathrm{~h} .{ }^{15}$ Secondly, the dried membranes were immersed in a solution of $60 \mu \mathrm{L}$ FDTS, $10 \mathrm{~mL}$ water and $4 \mathrm{~mL}$ methanol in a $50 \mathrm{~mL}$ bottle, which was sealed with a cap and placed in an oven at $50{ }^{\circ} \mathrm{C}$ for 1 day. Finally, the modified membranes were rinsed three times with ethanol and water to remove unreacted FDTS molecules, followed by air-drying in an oven at $60{ }^{\circ} \mathrm{C}$ for $2 \mathrm{~h}$ to remove the solvent. The modified dried membranes were sawed into pieces of appropriate sizes for use in different experiments.

An optical contact angle meter (Powreach JC2000D1) was used to measure the surface wettability at ambient temperature in air. Each contact angle was an average value of three values measured at different locations by using about $5.0 \mu \mathrm{L}$ liquid droplets. Highspeed video camera (Powreach JC2000D1) was used to capture the oil permeation behavior through the membrane. The cork membranes were coated with gold to avoid the influence of charge effects during observation by a field emission scanning electron microscope (FESEM, Hitachi SU8000). Surface elemental composition of cork membranes was investigated by an energy dispersive X-ray analyzer (EDAX) coupled to the FESEM and Perkin-Elmer PHI-5300 electron spectrometer with $\mathrm{Al} \mathrm{K} \alpha \mathrm{X}$-ray radiation.

The modified cork membrane was fixed between two glass tubes (diameter $\sim 1.7 \mathrm{~cm}$ ). The separating equipment is tilted to ensure the oil contact with the membrane considering that most oils have a density lower than water. Six kinds of oils and organic solvents in different density, including petroleum ether, hexane, chloromethane, xylene, diesel and kerosene, were used to investigate the oil and water separation ability of the membrane. They were stained by oil red and mixed with water that was stained by methylene blue. The different oil/water mixtures $(2: 1, \mathrm{v} / \mathrm{v})$ were poured into the top glass tube to separate oil from water solely driven by gravity. 

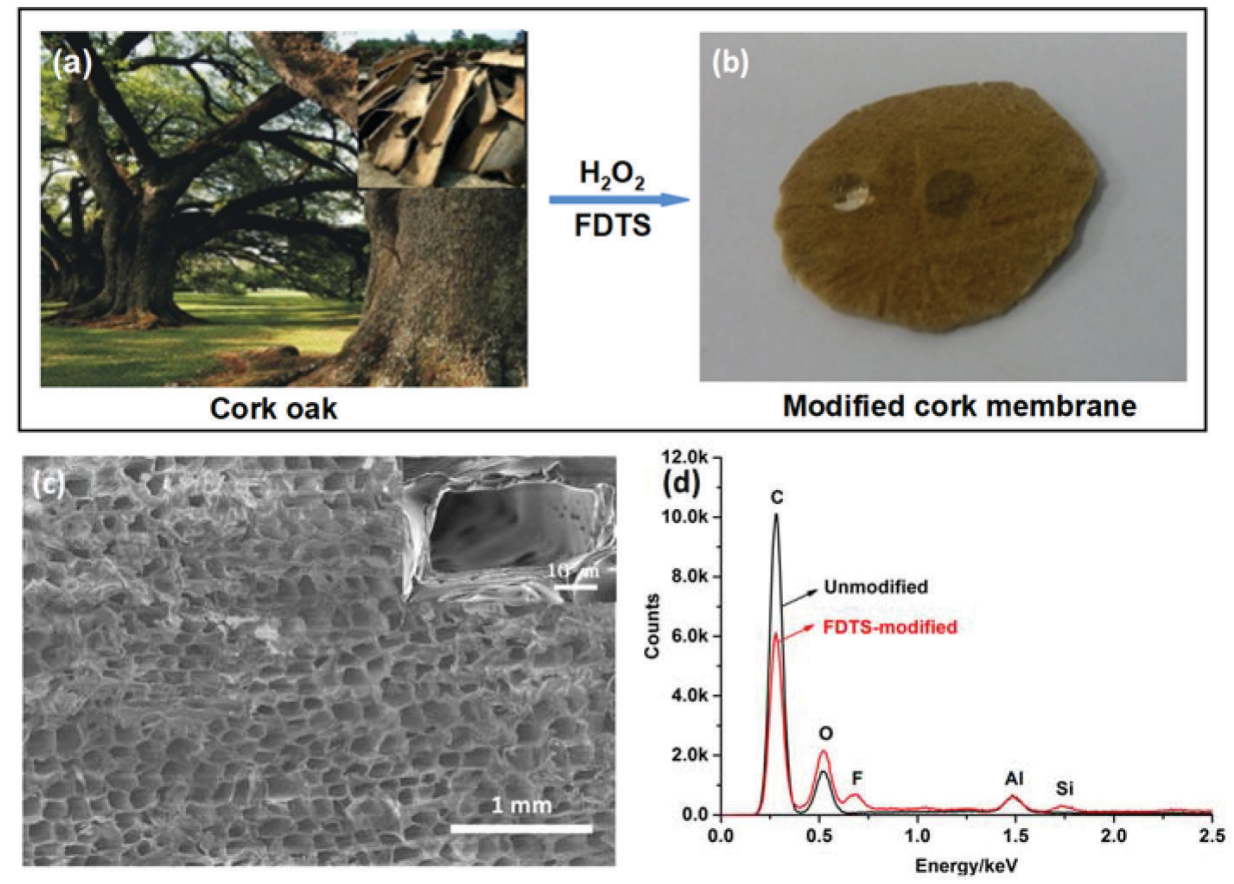

Figure 1. $(a \rightarrow b)$ Fabrication process of cork membrane with superhydrophobicity and superoleophilicity. (c) FESEM images of the modified cork membrane, The inset shows the magnified image of cell wall. (d) EDAX spectra of the modified cork membrane

\section{RESULTS AND DISCUSSION}

Membranes with an approximate thickness of $2.0 \mathrm{~mm}$ used in the experiment were prepared by sawing cork in the tangential section. For the pristine cork membrane, the contact angles of water and oil droplets on the membrane surface were approximately $127^{\circ}$ and $0^{\circ}$, respectively. After a water or oil droplet was dropped on it, as the slow water absorption into the membrane surface, its contact angle was decreased close to $0^{\circ}$ within approximately $3 \mathrm{~min}$, while the oil droplet immediately spread out and permeated into the membrane (e.g. kerosene permeation time within $0.05 \mathrm{~s}$ ). For the FDTSmodified cork membrane, the surface of cork membrane exhibited superhydrophobicity with water contact angle of approximately $156^{\circ}$ and superoleophilicity with oil contact angle of almost $0^{\circ}$. Water droplet maintained spherical shapes on the membrane surface and could easily roll off from the slightly tilted surface (a slide angle of less than $10^{\circ}$ ), while oil droplets such as kerosene could rapidly wet and spread on the cork membrane, and permeate through the cork membrane within 0.1 $\mathrm{s}$, still exhibiting a superoleophilic property (Figure 1b). The reason is that the FDTS introduced into the surface greatly decreases the surface energy, which rendered the surface energy of the membrane much less than that of water and close to that of oils. In addition, surface structures are small enough at the micrometer scale, superhydrophobicity and superoleophilicity of the cork membrane can be achieved.

The superhydrophobic and superoleophilic properties of the cork membrane are controlled by both the chemical composition and the surface morphological structure. Cork has an orderly and closelypacked structure of cells and there are not spaces between cells. Figure 1c shows the typical tangential sectional view of the modified cork which has honeycomb-type cellular arrangement with an average cell diameter of $30 \mu \mathrm{m}$. Cell rows are composed by many small hexagonal cells which are stacked base to base. The cell rows align parallelly with each other to form cork. ${ }^{14}$ Some cellular cavities were covered by cellular wall which might be bent in the process of sawing. The average cell wall thickness of cork was about $2 \mu \mathrm{m}$. In some cell walls, circular plasmodesmata with a diameter of about $0.3 \mu \mathrm{m}$ form channels between neighboring cells (Figure 1c inset). Liquids and gases can flow through plasmodesmata channels and capillaries of the cork walls. ${ }^{16,17}$ The separation of the cell wall into lamellae by soaking in solvents made the membrane rougher, which provided the required roughness to realize superhydrophobicity and superoleophilicity.

Chemically, the cork cell wall is composed of 53\% suberin and $26 \%$ lignin. ${ }^{15}$ Elemental analysis results indicate that about $99 \%$ of the raw cork is composed of carbon, oxygen and hydrogen. ${ }^{13}$ EDAX analysis was used to characterize the elementary composition of the membrane before and after modified with FDTS. For the pristine cork membrane, only two signals assigned to $\mathrm{C}$ and $\mathrm{O}$ could be observed in Figure 1d (signals for $\mathrm{Al}$ came from the aluminum specimen stage). For the membrane modified with FDTS, apart from the signals of $\mathrm{C}$ and $\mathrm{O}$, new signals for $\mathrm{F}$ and $\mathrm{Si}$ were observed, which was in accordance with the chemical composition of the FDTS. These results indicate that the membrane is successfully modified with FDTS, which is consistent with the result reported previously. ${ }^{18}$

Moreover, the surface composition of the membrane was further determined by XPS analysis (Figures2a and 2b). Before the membrane modified with FDTS, XPS spectra show only two strong peaks located at $285.9 \mathrm{eV}$ and $533.4 \mathrm{eV}$ which are assigned to $\mathrm{C} 1 \mathrm{~s}$ and $\mathrm{O} 1 \mathrm{~s}$, respectively. After the membrane modified with FDTS, the new peaks of F 1s at $690.2 \mathrm{eV}, \mathrm{F}$ KL1 at $617.0 \mathrm{eV}, \mathrm{Si} 2 \mathrm{p}$ at 103.7 $\mathrm{eV}$ and $\mathrm{Si} 2 \mathrm{~s}$ at $149.0 \mathrm{eV}$ can be clearly observed (Figure $2 \mathrm{a}$ ). The high-resolution spectra of C 1s show a new peak at $292.8 \mathrm{eV}$ due to C-F bonds from FDTS. ${ }^{18,19}$ The above results confirm that the successful chemical grafting FDTS into the cork membrane. After modification, the intensity of the characteristic signals for $\mathrm{O}$ is still relatively strong, which suggests the FDTS modified on the cork membrane is extremely thin. This means that the channel size of the cork membrane is not obviously altered by FDTS.

To evaluate the permeability of membrane solely by the gravity, the equation (1) was used to calculate the permeability $(P)$ of the membrane: ${ }^{20}$

$$
P=V / A t
$$

where $V(100 \mathrm{~mL})$ is the volume of oil that permeates the membrane, 

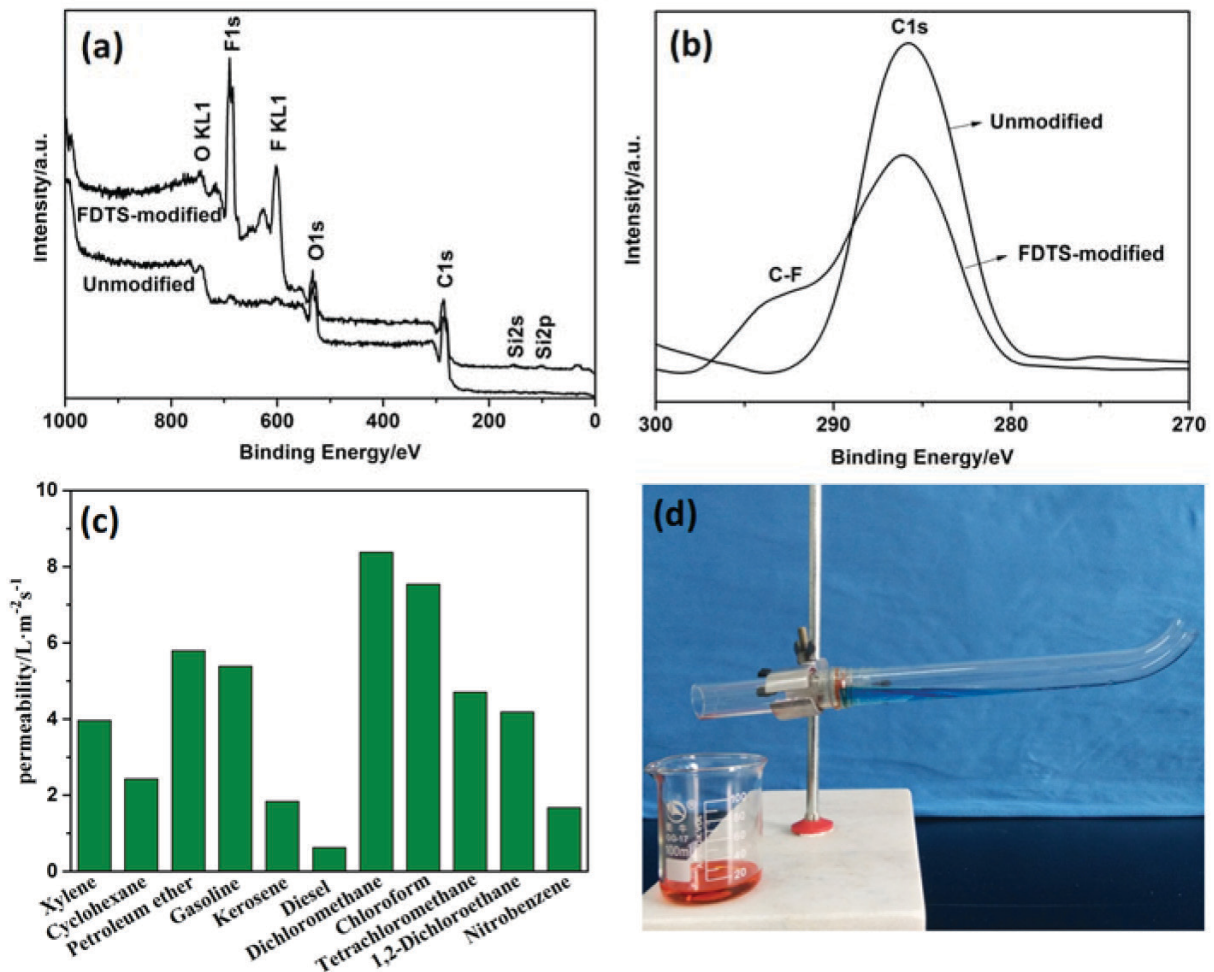

Figure 2. (a) XPS spectra of the cork membrane before and after FDTS modification. (b) The high-resolution spectra of C 1s of the FDTS-modified cork membrane. (c) Permeability of the modified membrane to various oils. (d) The separation of a kerosene/water mixture $(2: 1, v / v)$ with the device at a $15^{\circ}$ tilt angle

$A\left(2.3 \mathrm{~cm}^{2}\right)$ is the valid permeation area of membrane and $t$ is the needed permeation time of oil. The cork membrane with a thickness of $2.0 \mathrm{~mm}$ which was clamped between two glass tubes with the same diameter. For each test, $100 \mathrm{~mL}$ liquid was poured into the upper glass tube. The permeability to oils was above $0.63 \mathrm{~L} \mathrm{~m}^{-2} \mathrm{~s}^{-1}$, which indicated that the membrane could be used as a good filtration support (Figure 2c).

To evaluate the separation efficiency of the membrane, mixtures of various oils/water were separated by the modified membrane. The oil and water separation experiment device was performed as shown in Figure 2d. The separation efficiency of the cork membrane was defined as the volume ratio of the collected oil to the added oil. Figure $3 \mathrm{a}$ shows that the separation efficiencies for a series of oil and water mixtures $(2: 1, \mathrm{v} / \mathrm{v})$ are all above $99.1 \%$. Recyclability and stability of the membrane are key evaluation parameters in oil and water mixtures separation. After oil and water separation for 40 cycles, the kerosene/water mixture $(2: 1, \mathrm{v} / \mathrm{v})$ separation efficiency and the superhydrophobicity of the membrane remained almost unchanged (Figure 3b).
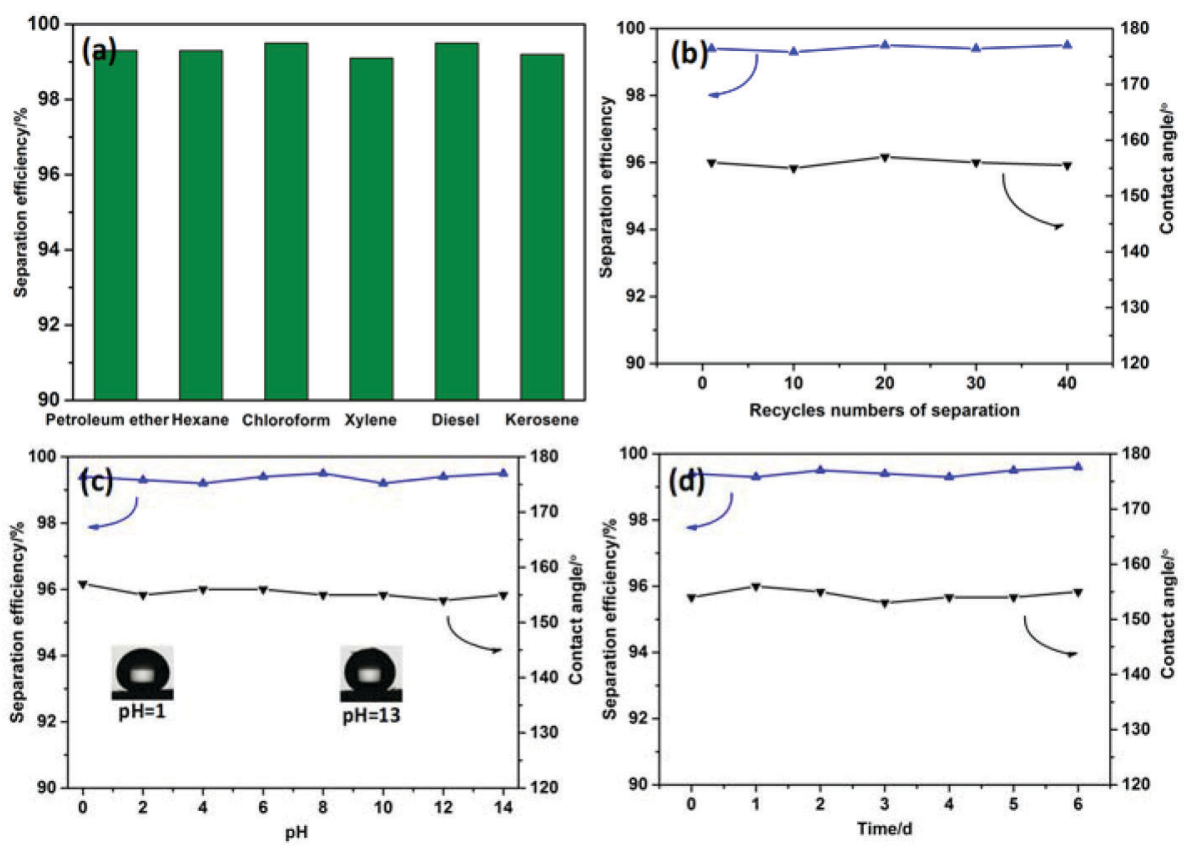

Figure 3. Oil and water separation and water contact angles studies of the modified cork membrane: (a) Separation efficiency for a series of oil and water mixtures. (b) after 40 separation cycles. (c) Exposed to water at different $\mathrm{pH}$. (d) at a temperature of $60{ }^{\circ} \mathrm{C}$ with a relative humidity of $90 \%$ 
When separating kerosene from water in the range of $\mathrm{pH}$ from 0 through 14 , the separation efficiencies are still above $99.1 \%$. It could be seen from Figure $3 \mathrm{c}$ that when the cork membrane surface was dropped different $\mathrm{pH}$ water, water contact angles varied only slightly and were always greater than $153^{\circ}$. The results showed that the $\mathrm{pH}$ of water has little effect on the stability of the membrane. It is known that if woods were heated in the air, they would carbonize very slowly above $70{ }^{\circ} \mathrm{C}$. Moreover, water uptake and swelling of cork in a humid environment are likely to affect cork thickness and channel size. In order to evaluate effect of temperature and humidity on the stability of the membrane, the modified cork membrane was heated at a temperature of $60{ }^{\circ} \mathrm{C}$ in an oven with a relative humidity of $90 \%$. Along with the increase of heating time up to 6 days, the contact angle for water and the separation efficiency for the oil and water mixture remained almost unchanged (Figure 3d).

\section{CONCLUSIONS}

In this study, based on the preponderance of hydroxyl groups of the cork, the superhydrophobic and superoleophilic cork membrane was fabricated by utilizing surface fluorination. The cork membrane with the special wettability of the surface and the channels of plasmodesmata and capillaries made it suitable for selectively separating water from oil and water mixture. Permeability (flux), contact angle and separation efficiency of the modified membranes were investigated in detail. It was found that in various harsh environments, the modified cork membrane maintained stable special wettability and high separation efficiency, excellent recyclability and stability, thus making the material a promising and highly energyefficient candidate for separation of oil and water. This method offers an opportunity to extend the range of practical applications for other woods.

\section{ACKNOWLEDGEMENTS}

This research was financially support by Natural Science Foundation of Henan Province of China (162300410208), the Foundation of Henan Educational Committee (16A150058) and the High-level Talent Foundation of Pingdingshan University (PXY-BSQD-2015003).

\section{REFERENCES}

1. Cheng, Q. F.; Li, M. Z.; Zheng, Y. M.; Su, B.; Wang, S. T.; Jiang, L.; Soft Matter 2011, 7, 5948

2. Shi, F.; Niu, J.; Liu, J. L.; Liu, F.; Wang, Z. Q.; Feng, X. Q.; Zhang, X.; Adv. Mater. 2007, 19, 2257.

3. Yu, Y. L.; Chen, H.; Liu, Y.; Craig, V.; Li, L. H.; Chen, Y.; Adv. Mater. Interfaces 2014, 1, 1300002.

4. Wang, Q. J.; Cui, Z.; Xiao, Y.; Chen, Q. M.; Appl. Surf. Sci. 2007, 253, 9054.

5. La, D. D.; Nguyen, T. A.; Lee, S.; Kim, J. W.; Yong, S. K.; Appl. Surf. Sci. 2011, 257, 5705.

6. Shang, Y. W.; Si, Y.; Raza, A.; Yang, L.; Mao, X.; Ding, B.; Yu, J. Y.; Nanoscale 2012, 4, 7847.

7. Li, H.; Zhao, X. Y.; Wu, P. F.; Zhang, S. X.; Geng, B.; J. Mater. Sci. 2016, 51, 3211.

8. Zhou, X. Y.; Zhang, Z. Z.; Xu, X. H.; Guo, F.; Zhu, X. T.; Men, X. H.; Ge, B.; ACS Appl. Mater. Interfaces 2013, 5, 7208.

9. Xue, C. H.; Ji, P. T.; Zhang, P.; Li, Y. R.; Jia, S. T.; Appl. Surf. Sci. 2013, $284,464$.

10. Fan, J. B.; Song, Y. Y.; Wang, S. T.; Meng, J. X.; Yang, G.; Guo, X. L.; Feng, L.; Jiang, L.; Adv. Funct. Mater. 2015, 25, 5368.

11. Dang, Z.; Liu, L. B.; Li, Y.; Xiang, Y.; Guo, G. L.; ACS Appl. Mater. Interfaces 2016, 8,1 .

12. Meyers, M. A.; Chen, P. Y.; Lin, Y. M.; Seki, Y.; Prog. Mater. Sci. 2008, 53,1 .

13. Pintor, A. M. A.; Silvestrealbero, A. M.; Ferreira, C. I. A.; Pereira, J. P. C.; Vilar, V. J. P.; Botelho, C. M. S.; Reinoso, F. R.; Boaventura, R. A. R.; Ind. Eng. Chem. Res. 2013, 52, 16427.

14. Miranda, I.; Gominho, J.; Pereira, H.; J. Wood. Sci. 2013, 59, 1.

15. Marques, A. V.; Pereira, H.; IAWA Journal 1988, 9, 337.

16. Fonseca, A. L.; Brazinha, C.; Pereira, H.; Crespo, J. G.; Teodoro, O. M.; J. Agric. Food. Chem. 2013, 61, 9672.

17. Fortes, M. A.; European Review 1993, 1, 189.

18. Du, C.; Wang, J. D.; Chen, Z.; Chen, D. R.; Appl. Surf. Sci. 2014, 313, 304.

19. Liu, H. Q.; Szunerits, S.; Pisarek, M.; Xu, W.; Boukherroub, R.; ACS Appl. Mater. Interfaces 2014, 1, 2086.

20. Wang, G.; He, Y.; Wang, H.; Zhang, L.; Yu, Q. Y.; Peng, S.; Wu, X. D.; Ren, T. H.; Zeng, Z. X.; Xuea, Q. J.; Green Chem. 2015, 17, 3093. 